\title{
Innovative Fast Time Simulation Tools for Briefing / Debriefing in Advanced Ship Handling Simulator Training and Ship Operation
}

\section{Knud Benedict ${ }^{a}$, Sandro Fischer ${ }^{a}$, Michael Gluch ${ }^{a}$, Matthias Kirchhoff ${ }^{a}$, Michele Schaub ${ }^{a}$, Michael Baldauf ${ }^{b}$, Burkhard Müller ${ }^{c}$}

The innovative "Simulation-Augmented Manoeuvring Design, Monitoring \& Control" system (SAMMON) based on Fast Time Simulation (FTS) technology was developed at the Institute for Innovative Ship Simulation and Maritime Systems (ISSIMS) of the Maritime Simulation Centre Warnemuende MSCW. The system consists of software modules for (a) Manoeuvring Design \& Planning, (b) Monitoring \& Control based on Multiple Dynamic Prediction and (c) Trial \& Training. It is based on complex ship dynamic models for rudder, thruster or engine manoeuvre simulation under different environmental conditions.

It is an effective tool for lecturing and demonstrating ships' motion characteristics, as well as for ship handling simulator training. It allows the trainee to immediately see the results of the actual rudder, engine or thruster commands, without having to wait for the real-time response of the vessel. The Maritime Simulation Centre of AIDA Cruises at Rostock /Germany and the CSMART Center for Simulator Maritime Training of Carnival Corporation at Almere /NL have some experience with the use of this new technology to improve simulator training in Advanced Ship Handling Training courses.

Examples of its application in briefing / debriefing and introductory lectures for simulator exercises specifically for typical cruise ships with Twin-Screw and Rudder systems will be presented in the paper and at the conference.

a. Hochschule Wismar, University of Applied Sciences - Technology, Business and Design, Dept. of Maritime Studies Warnemuende \& MSCW, Institute ISSIMS, Germany e-mail: knud.benedict@hs-wismar.de

b. World Maritime University, Malmoe, Sweden

e-mail: mbf@wmu.se

c. AIDA Cruises, Maritime Simulation Training Centre, Rostock, Germany

e-mail: burkhard.mueller@aida.de

This work is licensed under (cc) BY

\section{KEY WORDS}

$\sim$ Fast-time simulation

$\sim$ Manoeuvre planning

$\sim$ Navigation Simulator Training

\section{DESCRIPTION OF THE FAST TIME SIMULATION USE CONCEPT}

1.1. Need for Fast Time Simulation (FTS) and Simulation Support

Ship manoeuvring is and will remain a human-centred process in spite of anticipated further technological development. The most important elements of this process are human beings and the technical equipment supporting their efforts. However, most of the work still has to be done manually since even today almost no automation support is available either for routine or complex manoeuvres. There is as yet no electronic tool capable of demonstrating manoeuvring characteristics efficiently or designing an efficient manoeuvring plan - even in briefing procedures for ship handling training, the potential manoeuvres have to be "guessed" and drafted on paper or described by sketches and short explanations. The impact of wind or current is rather vaguely estimated based on experience.

However, new demands originating from IMO's e-navigation strategy to enhance safe, efficient and environmentally friendly navigation from berth to berth require the preparation of harbour approaches with complete berthing plans, especially by companies with high safety standards like cruise liners. These plans have to be agreed on by the bridge team, discussed and briefed with the pilot. Plan of potential manoeuvres needs to be developed - but only tentatively, by thinking ahead - by 
putting it on paper or describing it with self-made sketches and short explanations. The plans are drawn up manually, either on paper charts or electronic chart interface printouts, since the tools providing support for manoeuvring planning have yet to be developed.

Ship Handling Simulation for simulator training has been proven to be highly effective. However, it is based on real time simulation, i.e. 1 second in computer calculation time represents 1 second in real world manoeuvring time. This means that in spite of all other advantages of full mission ship handling simulation, the process of collecting manoeuvring experiences remains utmost time-consuming. For instance, a training session for a berthing manoeuvre might take one hour - if the first attempt fails or an alternative strategy needs to be tried out, this second session takes an additional hour, which can hardly be considered efficient.

The Fast Time Simulation method will be used in the future to increase training effectiveness, as well as the safety and efficiency of real ship manoeuvring. Even when used on standard computers, it is capable of simulating a manoeuvre lasting about $20 \mathrm{~min}$ in 1 second computing time by using innovative simulation methods. Fast Time Simulation tools have been used in the research activities of the Institute for Innovative Ship Simulation and Maritime System ISSIMS at the Maritime Simulation Centre Warnemuende, which is a part of the Department of Maritime Studies of Hochschule Wismar, the University of Applied Sciences - Technology, Business \& Design in Germany. They have been further developed by start-up company Innovative Ship Simulation and Maritime Systems (available at: ISSIMS GmbH Web page).

\subsection{Overview of Fast Time Simulation (FTS) Software Modules}

A brief overview of FTS tool modules is provided, together with their potential application:

SAMMON is the brand name of an innovative "Simulation Augmented Manoeuvring - Design, Monitoring \& Control" system, consisting of four software modules for Manoeuvring Design \& Planning, Monitoring \& Conning with Multiple Dynamic Prediction and Simulation \& Trial. The modules are as follows:

- Manoeuvring Design \& Planning Module: designing ship manoeuvring concepts as a "Manoeuvring Plan" for harbour approach and berthing manoeuvres (steered by virtual handles on the screen by the mariner).

- Manoeuvring Monitoring \& Conning Module with Multiple Dynamic Manoeuvring Prediction: monitoring of ship manoeuvres during simulator exercises or monitoring of real ship manoeuvres using bridge handles, simultaneous display of manoeuvring plan and predicted manoeuvres; calculation of various prediction tracks for full ship dynamic simulation and simplified route prediction, like Look Ahead for future ship motion.

- Manoeuvring Simulation Trial \& Training Module: ship manoeuvring simulation on laptop to view and exercise the manoeuvring concept (providing it has the function of a monitoring tool; steered by virtual handles on the screen).

These modules are suitable for application both:

- in maritime education and training to support ship manoeuvring exercises by demonstrating and facilitating the explanation of manoeuvring technology details and, more specifically, to prepare manoeuvring training in the SHS environment, i.e. by developing manoeuvring plans in briefing sessions, supporting manoeuvring during the exercise run and assisting with replay analysis and in discussions on quick demonstration of alternative manoeuvres during debriefing sessions; and

- $\quad$ onboard to facilitate the manoeuvring of real ships, e.g. by compiling manoeuvring plans for challenging harbour approaches requiring complex berthing / unberthing manoeuvres, assisting steering by providing multiple predictions during the manoeuvring process and even by supporting result analysis, as well as for onboard training with the Simulation \& Trial module.

SIMOPT is an FTS-based Simulation Optimiser software module for standard manoeuvre optimization and ship math model parameter modification applicable in simulator ships, FTS Simulation Training Systems and onboard SAMMON System applications.

SIMDAT is a software module for analysing simulation results obtained both from SHS or SIMOPT simulations and real ship trials: data on manoeuvring characteristics can be automatically retrieved and comfortable graphic tools are available for displaying, comparing and assessing the results.

The use of SIMOPT and SIMDAT modules for simulator ship model parameter tuning was described in earlier papers (Benedict at al., 2003; Schaub at al., 2015) as was the application of Multiple Dynamic Prediction \& Control modules (Benedict at al., 2006) in onboard use as a steering assistance tool. This paper focuses on the potential of the SAMMON software to support the lecturing and briefing / debriefing process with elements specifically designed for simulator training in the framework of Advanced Ship Handling in Maritime Simulation \& Training Centre MSTC of the AIDA Cruises Company at Rostock / Germany.

\section{USE OF FTS FOR LECTURING AND FAMILIARISATION}

\subsection{Stopping - Using Speed Vector as Stopping Distance Indicator}

One of the elements of simulator training courses is familiarisation with a ship's manoeuvring characteristics and 
their practical application - Fast Time Simulation is a smart tool shortening and raising the successfulness of this process. The following example deals with a ship's stopping capability. Cruise ship "AIDAblu" was used in examples in this paper; her dimensions are: length $L p p=244.6 \mathrm{~m}$, beam $B=32.2 \mathrm{~m}$ draft $T=7.00 \mathrm{~m}$. She has two pitch propellers and two rudders, two thrusters at the bow and two at the stern.

To get an overview of the ship's stopping distances when navigating at several different speeds and with varying astern

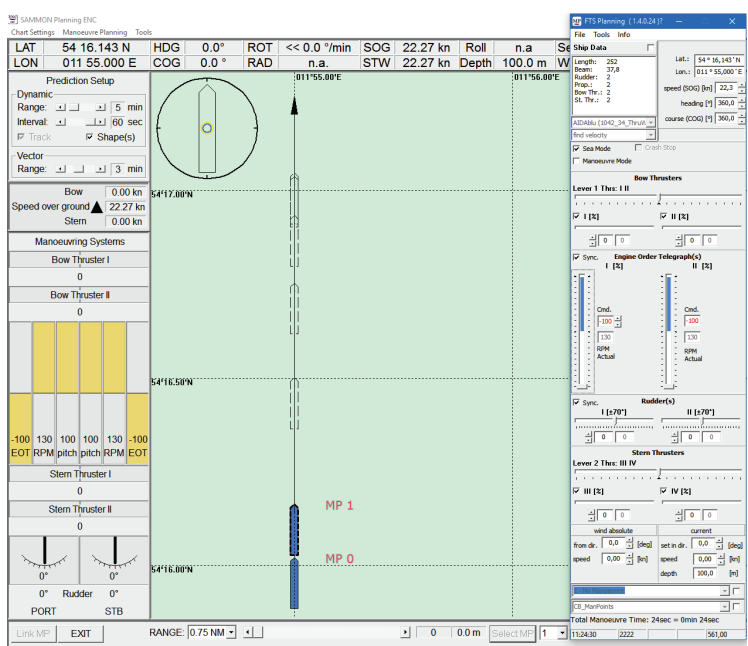

power, test trials could be conducted either with the Design \& Planning tool (Figure 1) or with the SIMOPT and SIMDAT program (Figure 2).

The Planning tool (Figure 1) allows the ship to be placed in the ENC window, in an initial MP 0 position, where the initial speed can be adjusted using the handles in the right window. The ships can then be moved using the slider at the bottom of the ENC window, e.g. into a position after $1 \mathrm{~min}$, where MP 1 is set.

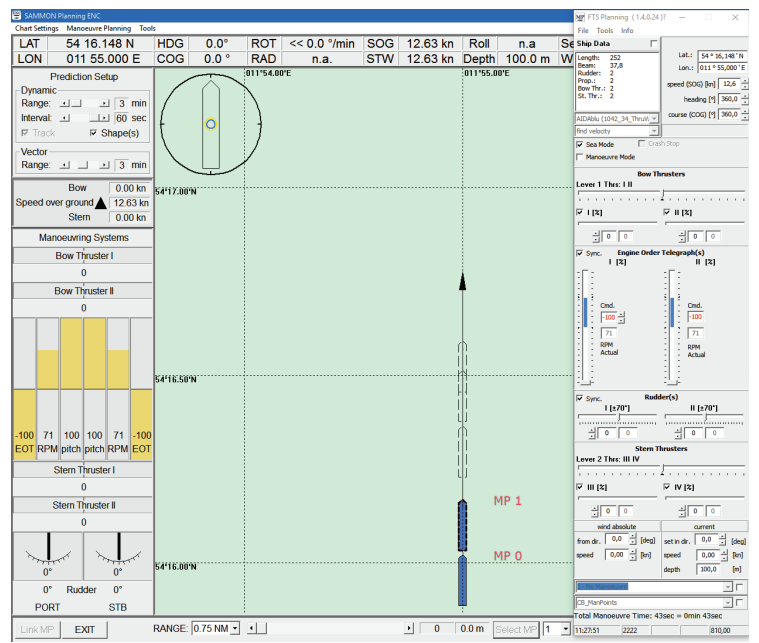

Figure 1.

Display of the Manoeuvring Design \& Planning Module: Two stopping manoeuvres for AIDAblu at different speeds to full astern (EOT $=-100 \%$ ):

- Left: crash stop from full ahead (EOT=+100\% for $22,2 \mathrm{kn}$ ) at MP1

- Right: stopping manoeuvre from half ahead (EOT=+53\% for $12.6 \mathrm{kn}$ ) at MP1.

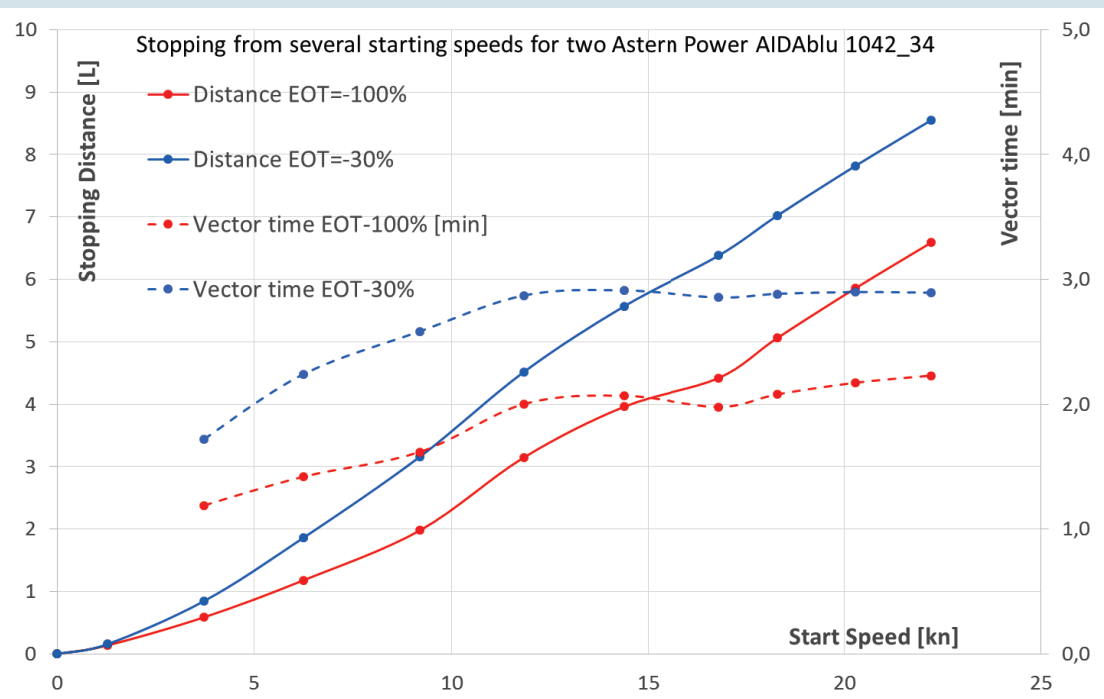

Figure 2.

Results of SIMOPT program for series of stopping manoeuvres for cruise ship AIDAblu (Computing time 17 seconds): Stopping diagram for distances (solid lines) and respective speed vector length times (dotted lines) (SIMDAT). 
Then handles are used to reverse the engine to EOT $=-100 \%$ and one can immediately see the ship's maximum stopping distance and stopping position in the ENC window.

In case of application of this stopping behaviour during voyage or in ports, visualising stopping distances in the ECDIS or RADAR could be helpful. The SAMMON Monitoring tool allows for high-level prediction of a ship's trail in case of change of the EOT or any other handle position after only 1 second (see Figure 15). Until this sophisticated dynamic prediction tool becomes available on the bridge, the speed vector can be used as an alternative.

The basic idea is to adjust the speed vectors' length to stopping distance: the required speed vector length can be easily calculated from the well-known formula speed = distance /time, i.e. time $=$ distance $/$ speed .

This equation helps us calculate Vector time: tvector=Stopping distance / Starting speed,

e.g. Crash Stop Stopping Distance of $1600 \mathrm{~m}$, given the starting speed of $22 \mathrm{kn}(12 \mathrm{~m} / \mathrm{s})$ :

tvector $=1600 \mathrm{~m} / 12 \mathrm{~m} / \mathrm{s}=138 \mathrm{~s}=2.18 \mathrm{~min}$

If these calculations are performed for all stopping distances of the solid lines in Figure 2, we get the dotted graphs. The result is that vector time is 2.5 minutes (blue dotted line) for all crash stop manoeuvres (blue line) at Full Astern; this is illustrated in Figure 1 where the ship comes to a stop prior to the expiry of the $3 \mathrm{~min}$ speed vector. Therefore, the conclusion might be that setting the speed vector to tvector $=3 \mathrm{~min}$ would give us an extra safety distance - it would even allow stopping the ship with the astern power of a mere EOT $=-30 \%$ !

\subsection{Effect of Rudders and Thrusters on Swept Path and Pivot Point}

In many situations occurring in narrow fairways and limited space, the manoeuvring space and the swept path are of utmost importance. Figure 3 illustrates that the swept path in turning manoeuvres is much bigger in rudder than thruster manoeuvres.

If turning is achieved by means of a rudder, it produces a lift force similar to that of a wing of an airplane but in the horizontal plane: the force is pointing outward to port side. Then a drift angle ß sets in and the ship's hull starts to act like a "wing" with lift force to starboard at the fore part of the ship; this force generates the so called "unstable moment" trying to increase the drift angle. Therefore, when turning motion $r$ develops, it causes centrifugal forces to act on the centre of gravity of ships and hydrodynamic masses. A damping force sets in due to rotation, acting like a "curved profile" and producing a moment in the opposite direction to balance the unstable moment in the circular motion. It has the same effect as "counter rudder", since it counteracts both the initial rudder moment and the unstable moment until an equilibrium is established in a steady state of circular turning.
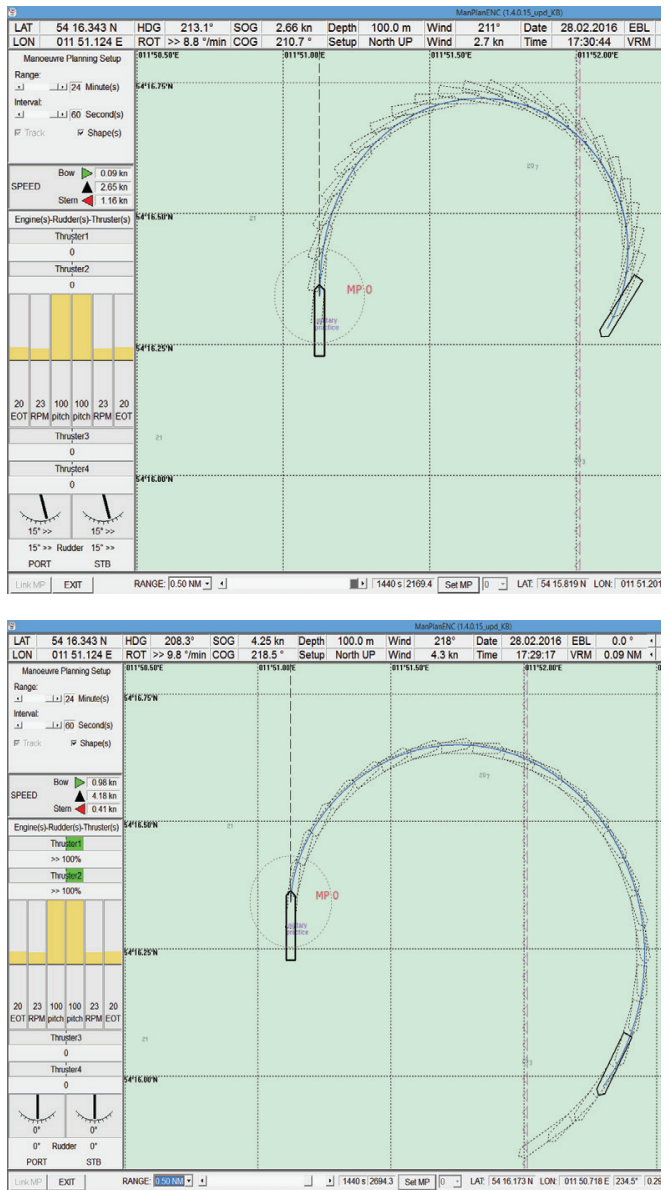

Figure 3.

Comparison of a ship's path when turning with rudders or thrusters, using SAMMON Design \& Planning tool in forward motion at EOT $=+20 \%$ ahead:

- Top: turning with rudder STB $15^{\circ}$, thruster $0 \%$

- Below: turning with bow-thruster $100 \%$ STB, rudder $0^{\circ}$.

The development of the Turning Circle Manoeuvre ends with a steady state, i.e. an equilibrium in balancing the transverse forces and moments.

If the ship starts turning with a bow thruster, there is no drift angle - it is not required (or even becomes negative if the thruster is too powerful!) to push the ship "inward" from its initial course because thruster force is already pushing it inward.

The drift angle and turning rate have an impact on the position of the pivot point (PP); the PP is located at the point in which crossflow speed (or the ship's transverse motion) is zero.

Where is PP and what affects its position? Figure 4 gives several examples of turning manoeuvres in ahead and astern motion and with rudder or thrusters. The following conclusions can be drawn: 
- PP position is flexible and directly dependant on the ship's motion, i.e. the ratio between drift and turning. E.g. at the beginning of the turn it is located mid ship and starts moving forward as the drift sets in; it remains in the fore part, on average at $1 / 3$ ship length behind the bow for rudder manoeuvres, i.e. aft for bow thruster manoeuvres.

- In case of wind, there might be wind drift in addition to the drift caused by rudder effect during turning, e.g. when turning in windy conditions: at the beginning of the turn, the pivot point is far ahead.

- The PP is not a suitable reference point for the discussion of acting forces due to its changing position - centre of gravity is preferable for understanding dynamic effects!

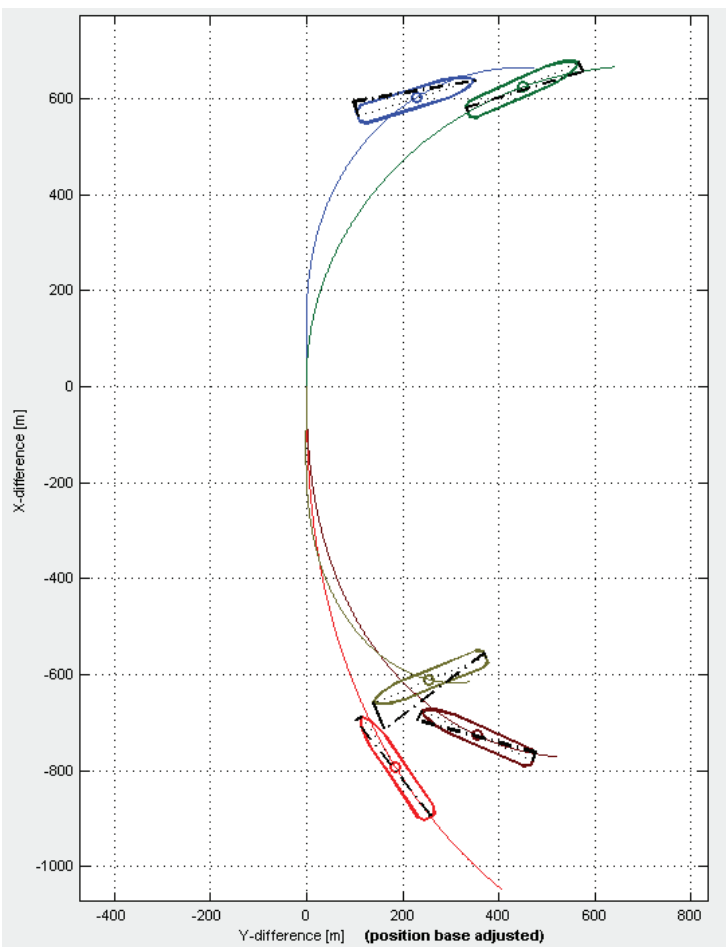

Figure 4.

Comparison of a ship's path and the location of the pivot point when the ship is turned with rudders or thrusters with SIMOPT \& SIMDAT:

a) Forward motion engine ahead EOT $=+20 \%$

- Blue: rudder $20^{\circ} \mathrm{STB}$, no thruster

- Green: bow thruster $100 \%$ STB

b) Astern motion engine astern EOT $=-20 \%$

- Red: rudder $20^{\circ} \mathrm{STB}$

- Brown: stern thruster $100 \%$ STB

- Grey: bow thruster -100 \% PT.
- In case of small drift angles, since PP is at mid ship, only minimum manoeuvring space is required, i.e. minimum swept path.

More effects on ship manoeuvring characteristics studied by SAMMON, available in (Benedict at al., 2016) for wind \& current and in (Benedict, 2016) for pivot point location and control.

\subsection{Effect of Split Engines and Rudders for Twin Screw - Twin Rudder Ships}

Many cruise ships and ferries have twin screw - twin rudder systems. Although these systems are normally continuously operated in synchronous mode during long voyage segments, when manoeuvring in ports, splitting the engines and propellers to allow their separate control might prove advantageous.

As seen in Figure 5, split engine manoeuvres can reduce the stopping distance:

Given the same speed with split engines, stopping distance at full astern is shorter, because one engine is already running astern, avoiding the reversing period altogether.

The split mode also has some advantages with respect to steering capability, since the rudder inflow from the ahead engine allows higher rudder forces to be used to stay on course (e.g. under strong wind) than when synchronised engines are used. In addition, turning can be improved as seen in Figure 6, leading us to the following conclusions: when split engines are used, the turning circle is smaller on the side where the prop is reversed, the ship reacts faster and has a smaller circular motion radius. Turning is likewise improved due to faster speed loss with split engines to that side, increasing the ratio of rudder forces to hull forces. However, if the ship is turning to the opposite side, the turning capability is reduced: this is why the ship needs the rudder angle of $\mathrm{PT}-4.4^{\circ}$ to balance the ship already moving along a straight track - i.e. the effective rudder change is nearly $40^{\circ}$ when turning STB, but only $30^{\circ}$ when turning PT.

\section{USE OF FAST TIME SIMULATION FOR SIMULATOR BRIEFING}

\subsection{Task Description - Introduction, Conventional Briefing and NEW CONCEPT}

During the exercise briefing, a navigation officer gets information about the harbour area, the starting situation and the environmental conditions in the area, on a conventional sea chart illustrated in Figure 7. The objective is to bring the ship through the fairway channel of Rostock Port from the north, turn and head back through the channel to berth the ship port side at the passenger pier. 

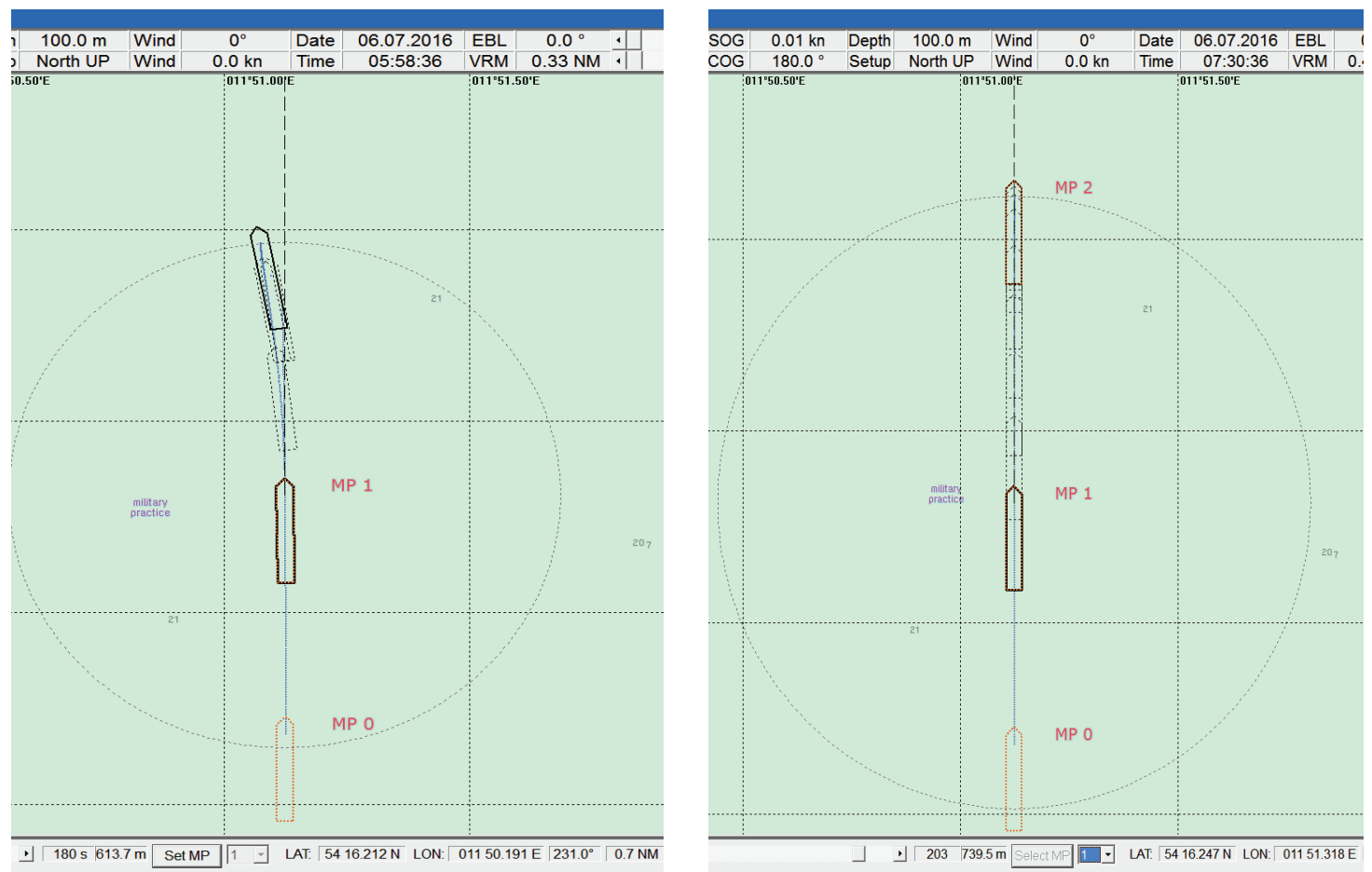

Figure 5.

Comparison of two different final situations after full astern to EOT $=-100 \%$, with the same initial speed of $11.4 \mathrm{kn}$ but different EOT settings:

- Left: from split engines STB $+70 \%$ \& PT $-20 \%$; Result: stopping distance $=0.33 \mathrm{~nm}$

- Right: from sync engines, $\mathrm{STB}=\mathrm{PT}=+48 \%$; Result: stopping distance $=0.40 \mathrm{~nm}$.
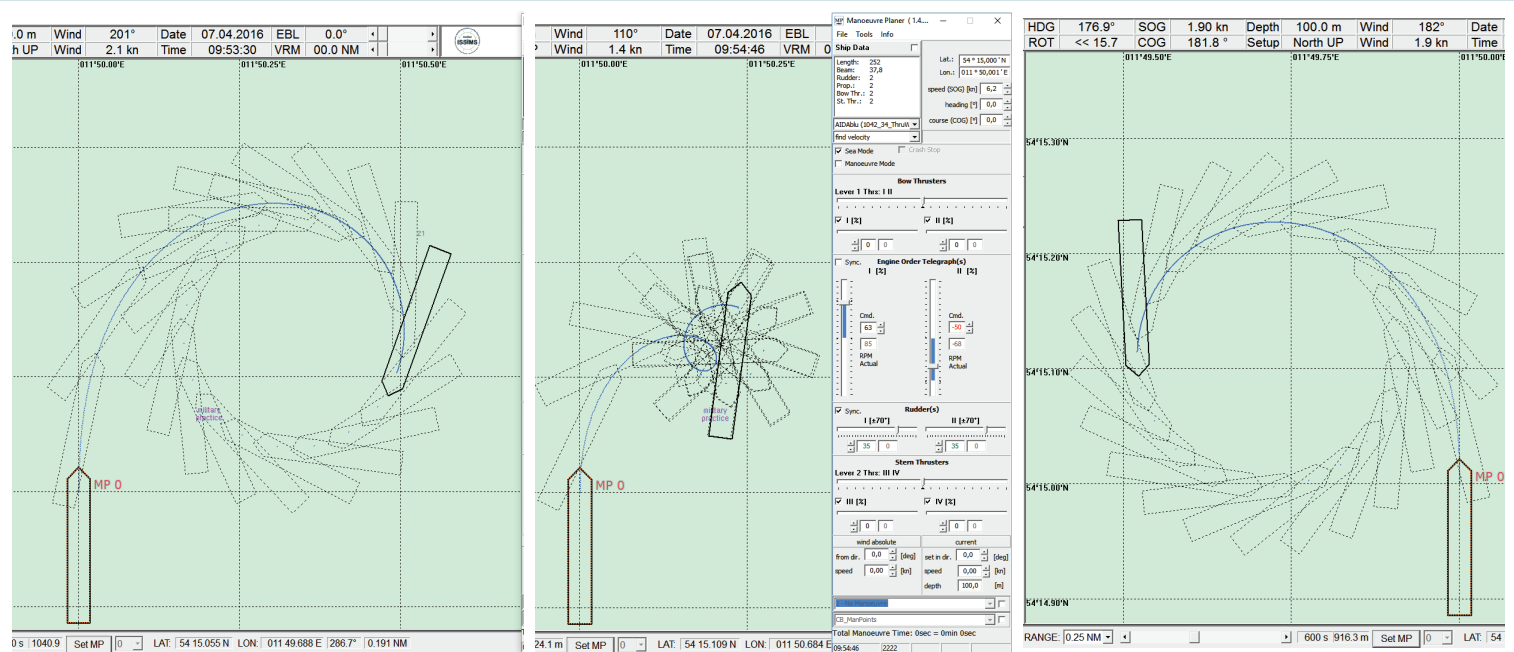

Figure 6.

Comparison of two turning manoeuvres beginning at the same initial speed of $6.2 \mathrm{kn}$, with constant speed rate on a straight track, to demonstrate the difference between sync and split engines:

- Left: standard turning manoeuvre with full rudders $35^{\circ} \mathrm{STB}$, standard sync engines from EOT $30 \%$ both STB and PT

- Centre: turning manoeuvre with full rudders $35^{\circ} \mathrm{STB}$, split engines PT engine $+63 \%$ ahead, STB engine $-50 \%$ astern

- Right: turning manoeuvre with full rudders $35^{\circ} \mathrm{PT}$, split engines PT engine $+63 \%$ ahead, STB engine $-50 \%$ astern. 


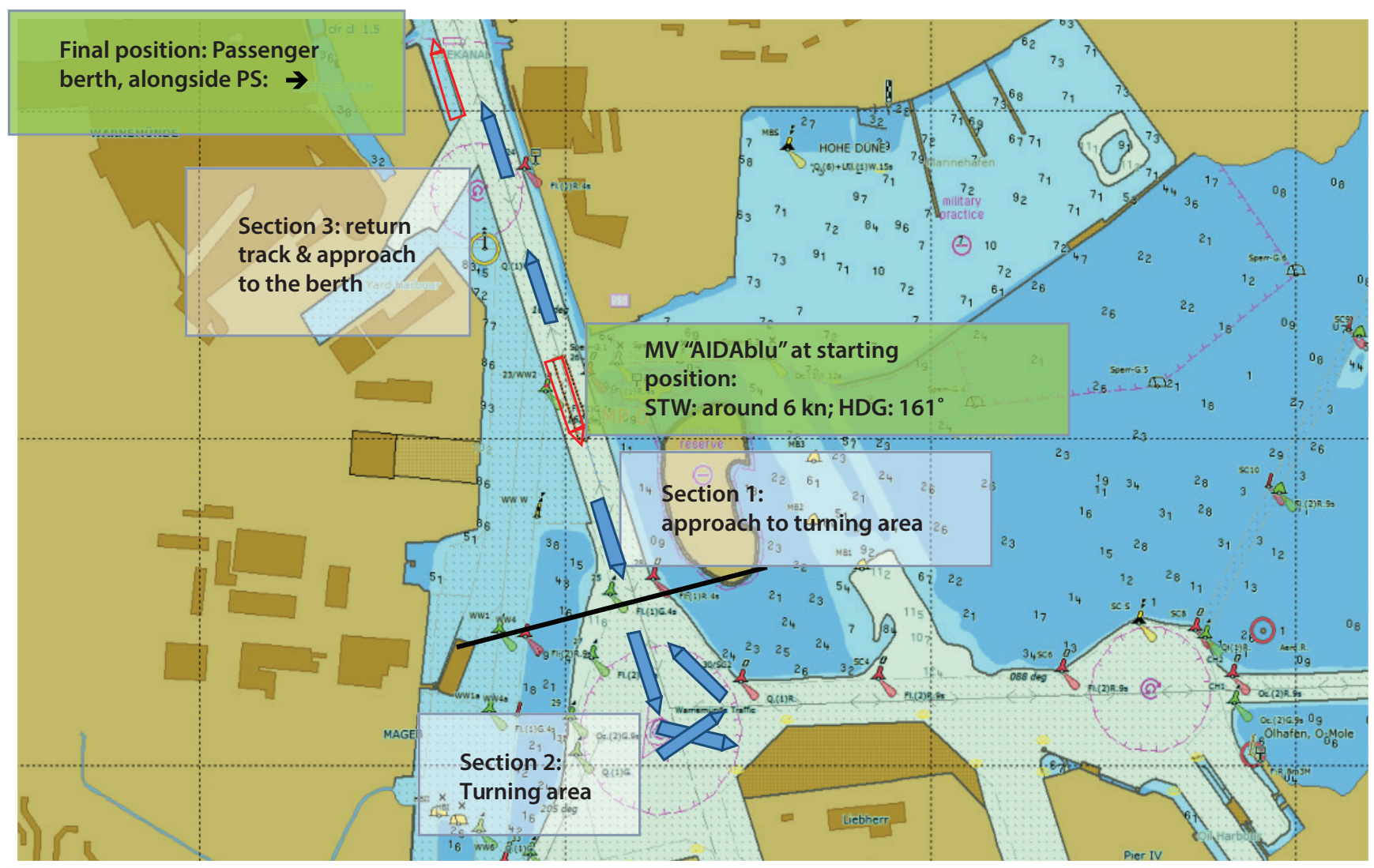

Figure 7.

Exercise area and environmental conditions in the Port of Rostock in a berthing scenario, divided into two manoeuvre planning sections and completed by guessing the desired positions of the ship (as contour).

The respective harbour area is divided into manoeuvring sections, with a specific goal:

1. Section 1: the ship's speed should be reduced until she is ready to be turned, SOG should be around $3 \mathrm{kn}$ to be prepared for section 2 .

2. Section 2: the ship should be turned and its course adjusted to re-enter the fairway in the course opposite to the final berth.

3. Section 3: the ship should be stopped and berthed.

In conventional briefing, only these rough indications of manoeuvring status can be used to develop a potential ship berthing strategy. In conventional berthing plans ship contours are positioned in WORD or POWER POINT drawings - the specific manoeuvres and engine rudder and thruster settings cannot be discussed in detail because specific manoeuvring characteristics can hardly be used in specific situations and real time simulation is too time consuming.

Fast time simulation allows the application of new individual exercise preparation methods with self-developed manoeuvring concepts:
- $\quad$ the Design and Planning tool allows us to develop a more detailed manoeuvring concept, i.e. the manoeuvring plan;

- the tool allows us to optimise the concept by several planning trials;

- $\quad$ pre-training using the Trial and Training Tool allows us to try out the concept on a laptop, in a real-time simulation.

\subsection{Briefing by Means of the „Manoeuvre Planning \& Design Module"}

\subsubsection{Basic exercise with no wind and no current}

New fast time simulation allows us to compile a manoeuvring plan representing a detailed strategy with settings specific to positions called manoeuvring points MP. Some basic functions and interface displays for fast time simulation in the Design and Planning Tool are illustrated in the following figures. Figure 8 explains the method in a sea chart environment represented by an interface which is a combination of an 


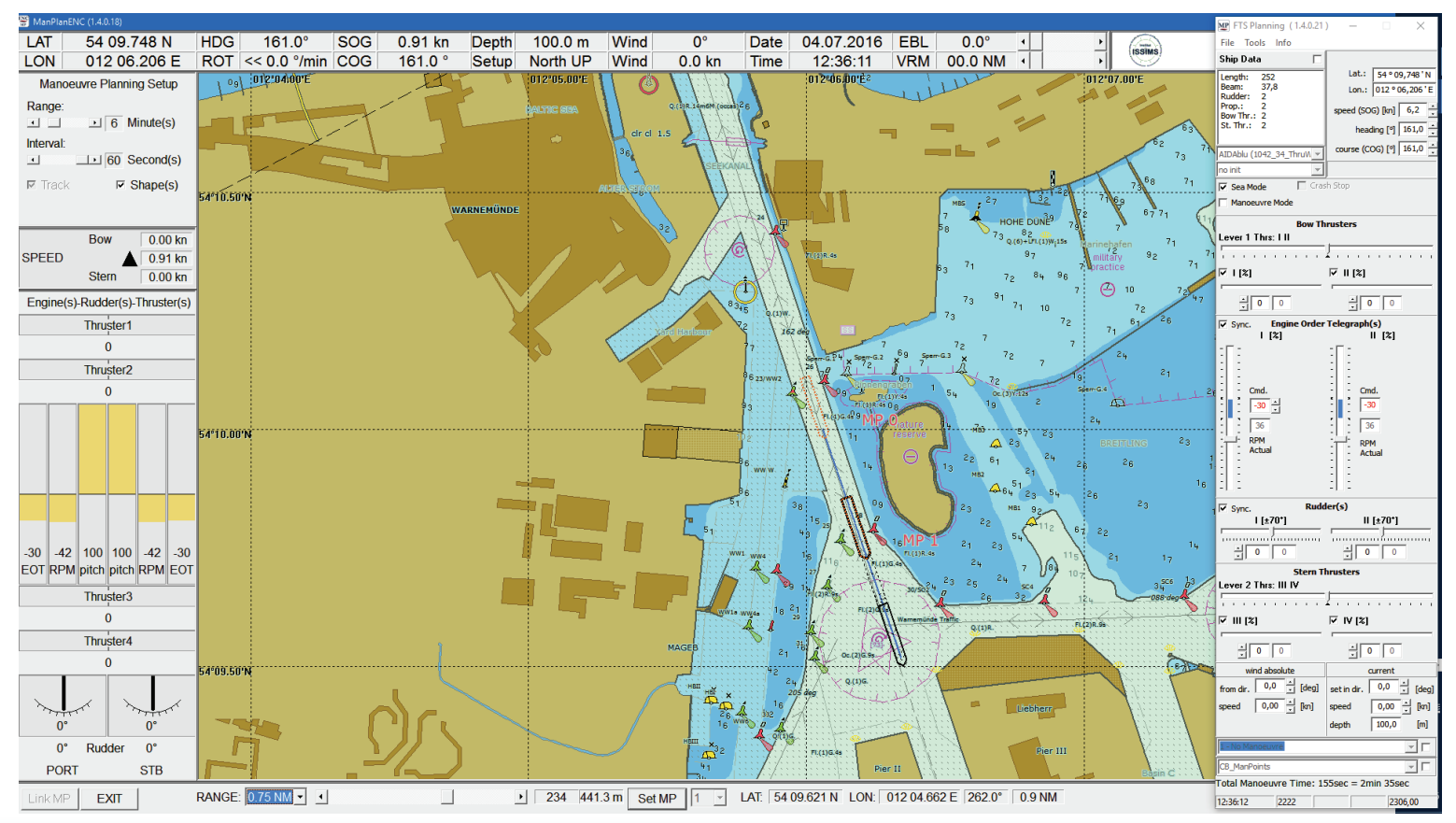

Figure 8.

Fast time planning on a sea chart: initial ship position MPO and predicted stopping manoeuvre at MP 1: based on set handle positions, the prediction already shows the ship reducing speed.

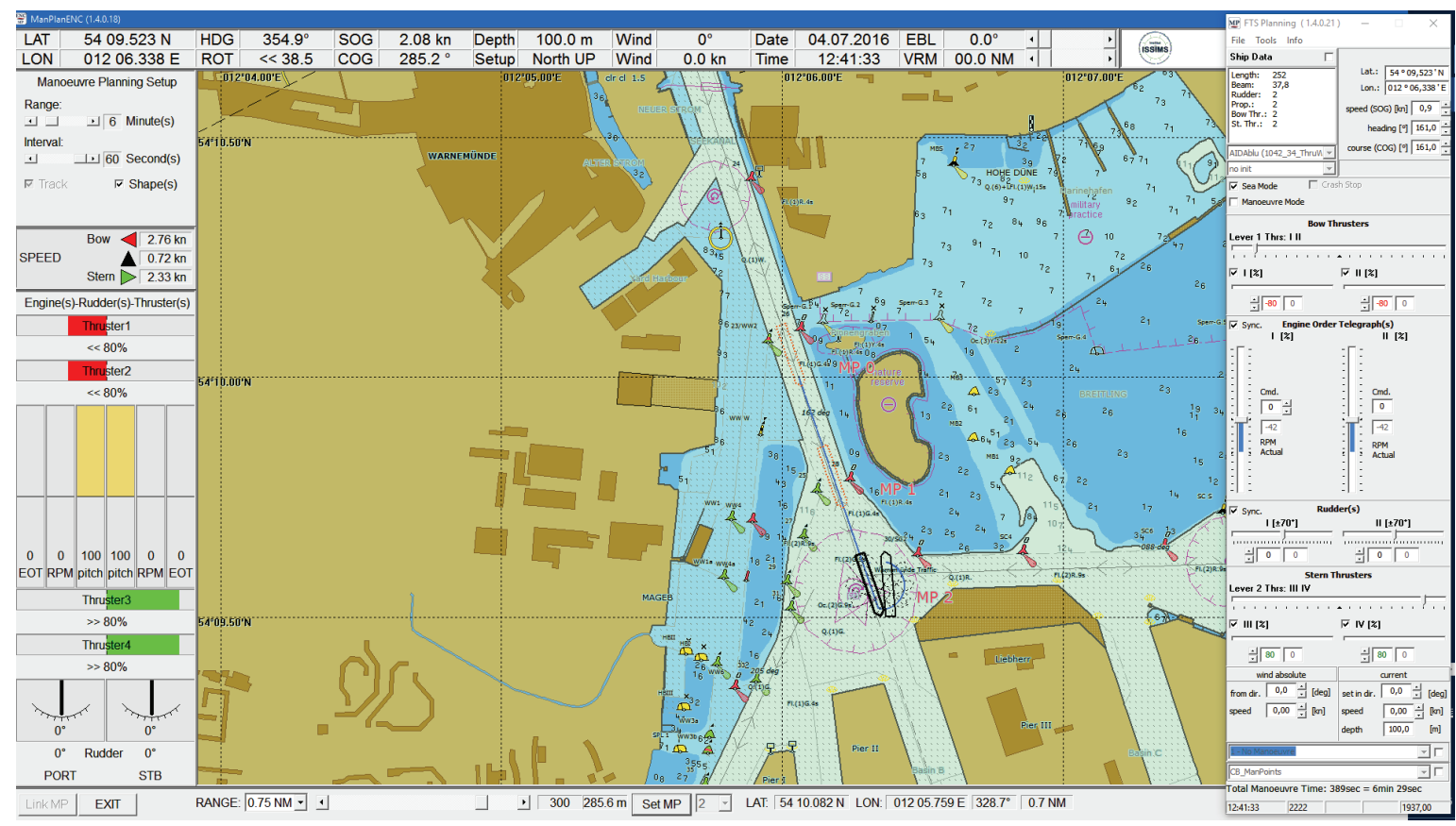

Figure 9.

Ship position at MP2 and prediction for the turning manoeuvre: the prediction shows the ship turning based on set handle positions of bow and stern thrusters operating at $80 \%$. 
electronic navigational chart ENC window (centre), interface window of a ship's steering panel (right) used to adjust the controls to the selected manoeuvring point MP and interface displaying the status of the actual current ship manoeuvring controls (left) at the next manoeuvring point MP, indicated as a red ship shape in the ENC.

The course of action will be illustrated by a series of figures to obtain a complete manoeuvring plan, including control actions required to be taken at designated manoeuvring points
$M P$ - first for simple conditions with no wind and currents to explain the fast time planning procedure:

In Figure 8, the initial position MP 0 is in the middle of the fairway, where the instructor has decided to position the ship. The ship has already been moved by using the slider at the ENC bottom to identify the next manoeuvring point MP 1: the stopping manoeuvres begin with EOT $-30 \%$. Based on handle positions, the ship is already predicted to slow down.

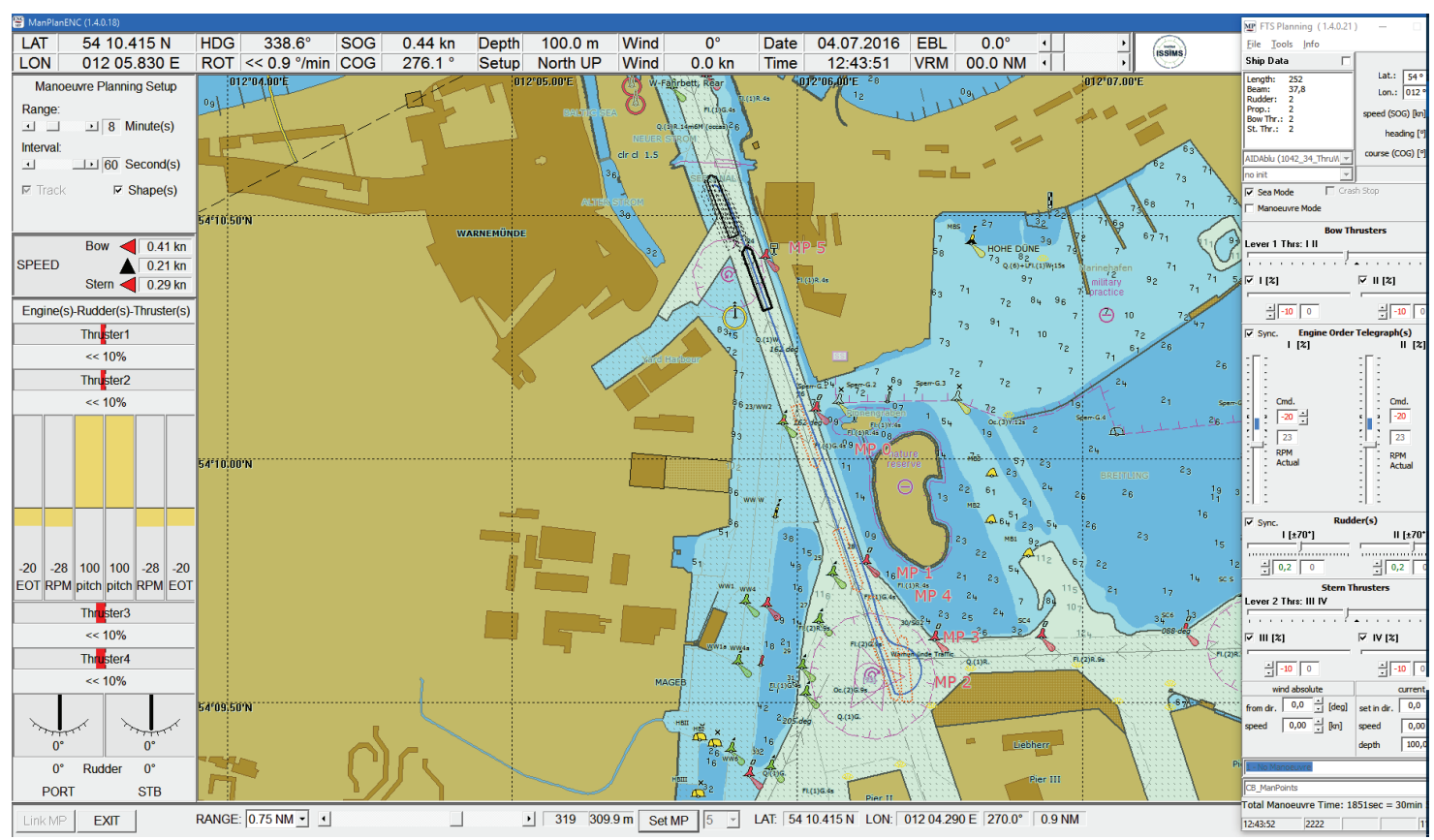

Figure 10.

Final part of the manoeuvring plan: the vessel is brought into a position parallel to the berth, to be pushed to the pier by thrusters from the next MP 6.

In Figure 9 the ship has almost come to a stop and turns by using the thrusters - the contour is moved to a position where the thrusters are stopped and the engines accelerate to return the vessel to the fairway in the opposite direction.

In Figure 10 the vessel is brought close to the berth and at MP5 the engines are reversed to reduce speed and stop the ship at a position parallel to the berth, to be pushed to the pier by thrusters from the next MP 6. The plan than requires an additional MP to reduce transversal speed shortly before berthing.

\subsubsection{Advanced exercise with strong wind}

The full potential of fast time simulation can be seen in difficult weather conditions. In Figure 11 the scenario has now to be re-enacted at $25 \mathrm{kn}$ wind from $61^{\circ}$. The initial position is the same as in the previous example but the trainee's first task is to find the balance condition in the fairway: after several attempts, drift angle of about $16^{\circ}$ and rudder angle of $3^{\circ}$ were set and the ship contour was moved to the buoys at fairway entrance. The next manoeuvring segment requires stopping and turning: the left side of

Figure 12 clearly shows that if the ship were simply to stop here as in the previous exercise, she would drift heavily with the wind. Therefore, the engines are split to support turning by the STB engine, while the PT engine goes astern.

In the final part of the manoeuvre, the crucial segments are difficult to execute due to strong wind on the return track in the opposite course: in Figure 13 the ship enters the fairway from the south, with strong wind from the bow, requiring heading, course and rudder adjustment. Splitting the engines is advantageous since the rudder is more effective when one engine operates with more power. In addition, the ship is better prepared to 


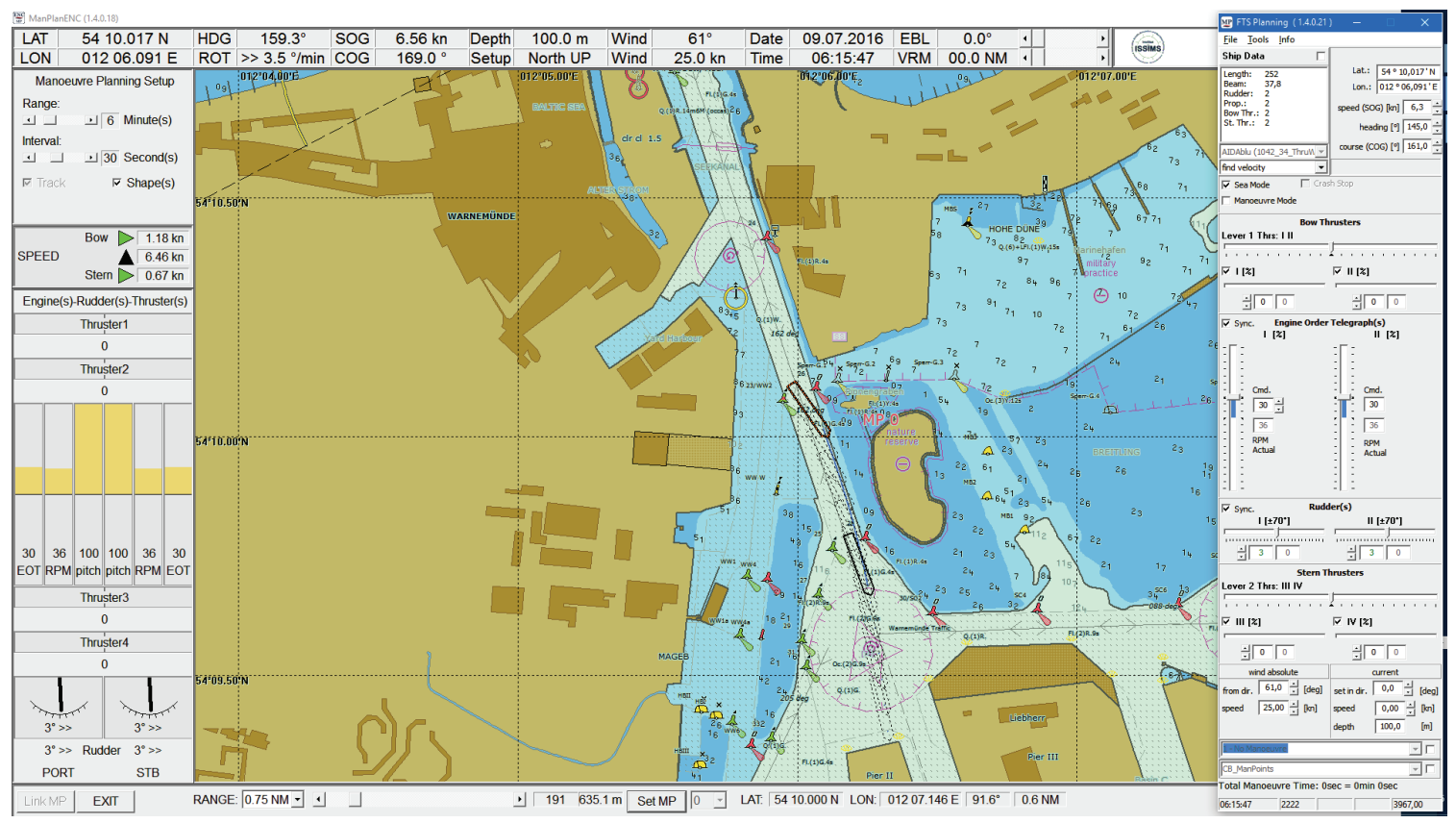

Figure 11.

Fast time planning on a sea chart under $25 \mathrm{kn}$ wind blowing from $61^{\circ}$ : initial ship position MPO and future course prediction with drift angle.
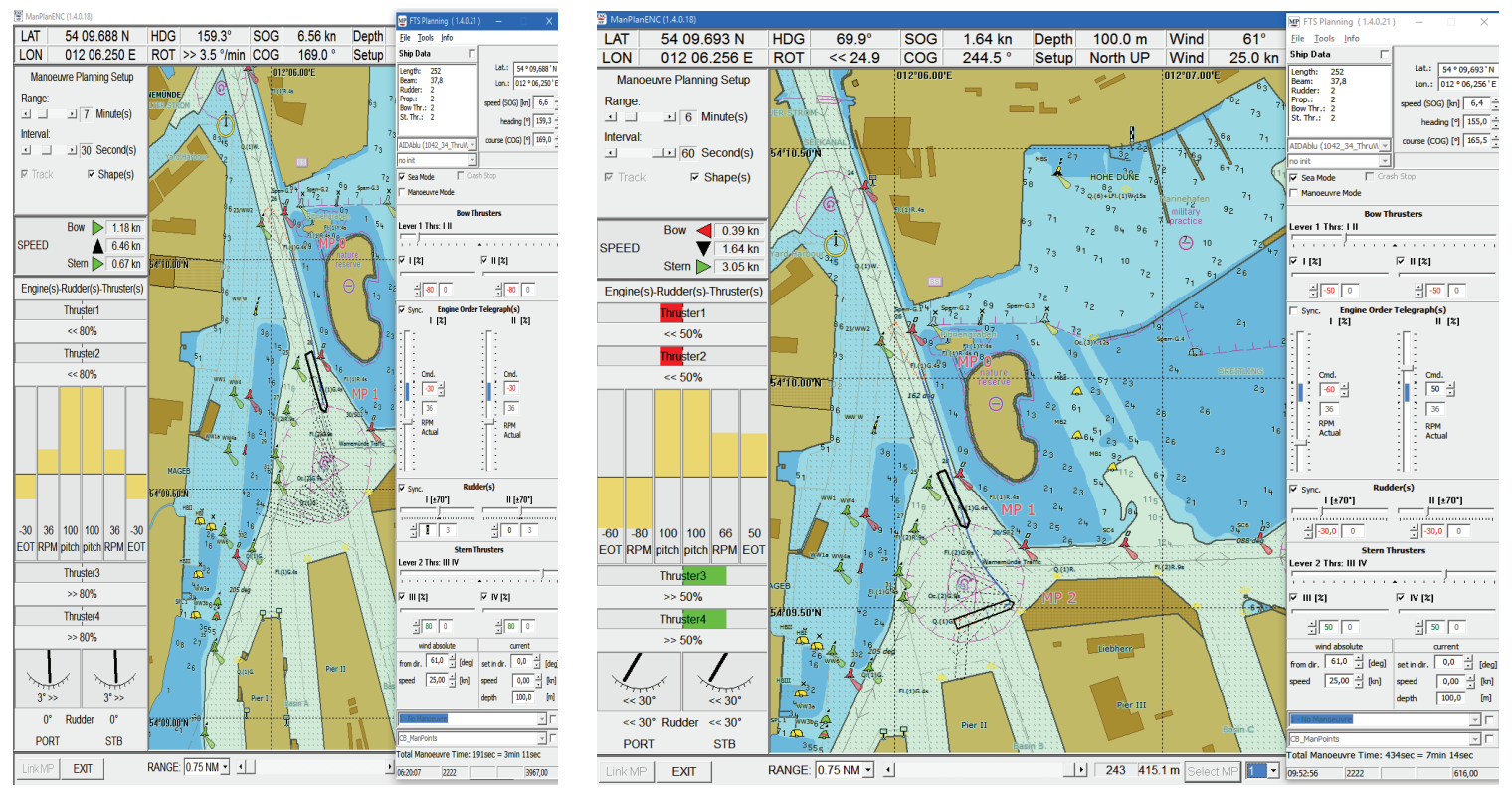

Figure 12.

Ship position at MP2 and turning manoeuvre prediction with two strategies:

- Left: turning with thrusters only (the same concept as without wind in Figure 9)

- Right: more powerful solution with split engines and rudder support. 

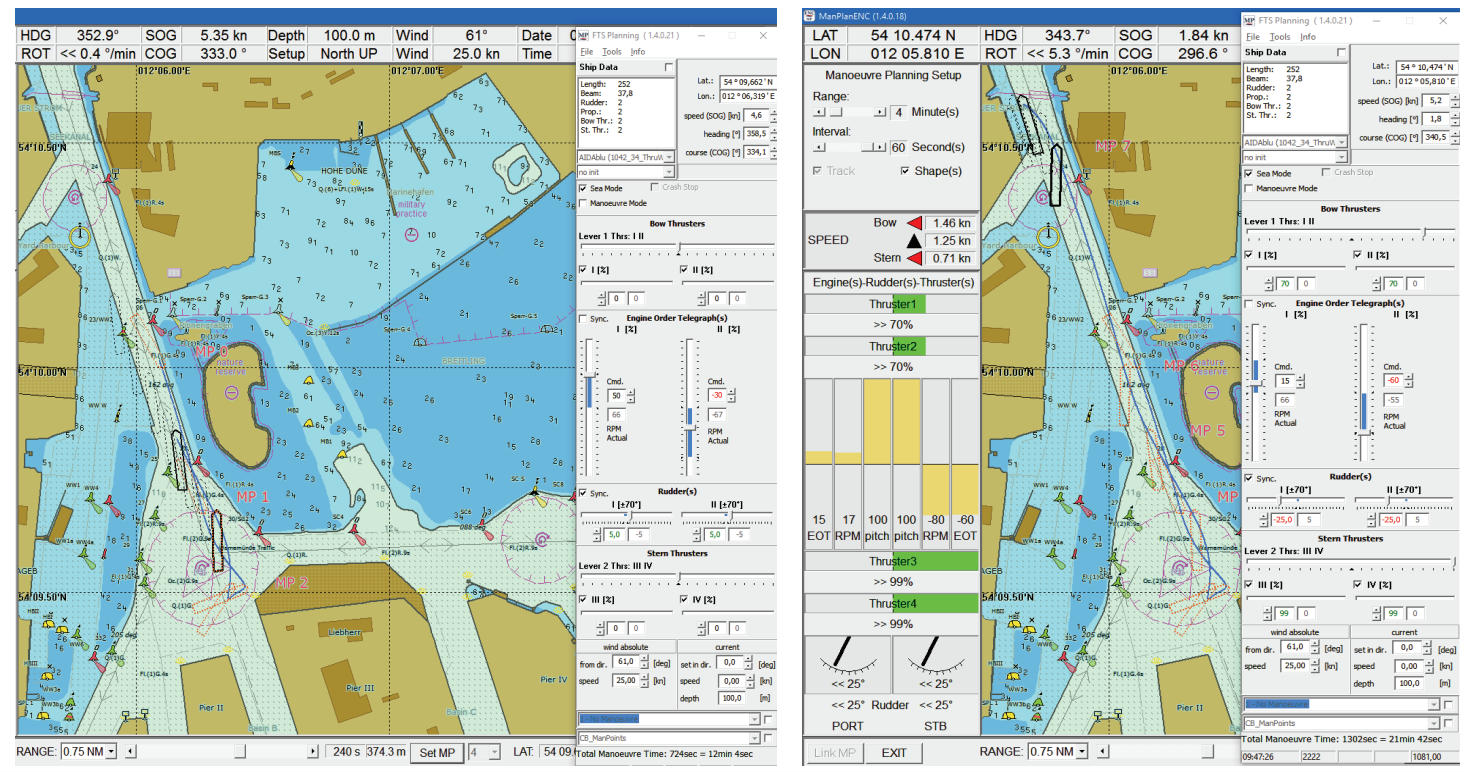

Figure 13.

Continued execution of the manoeuvring plan on the return track, in the opposite direction:

- Left: this time the ship enters the fairway from the south and heading, course and rudder are adjusted using split engines

- Right: the stopping manoeuvre intended to bring the ship into a position parallel with the berth.

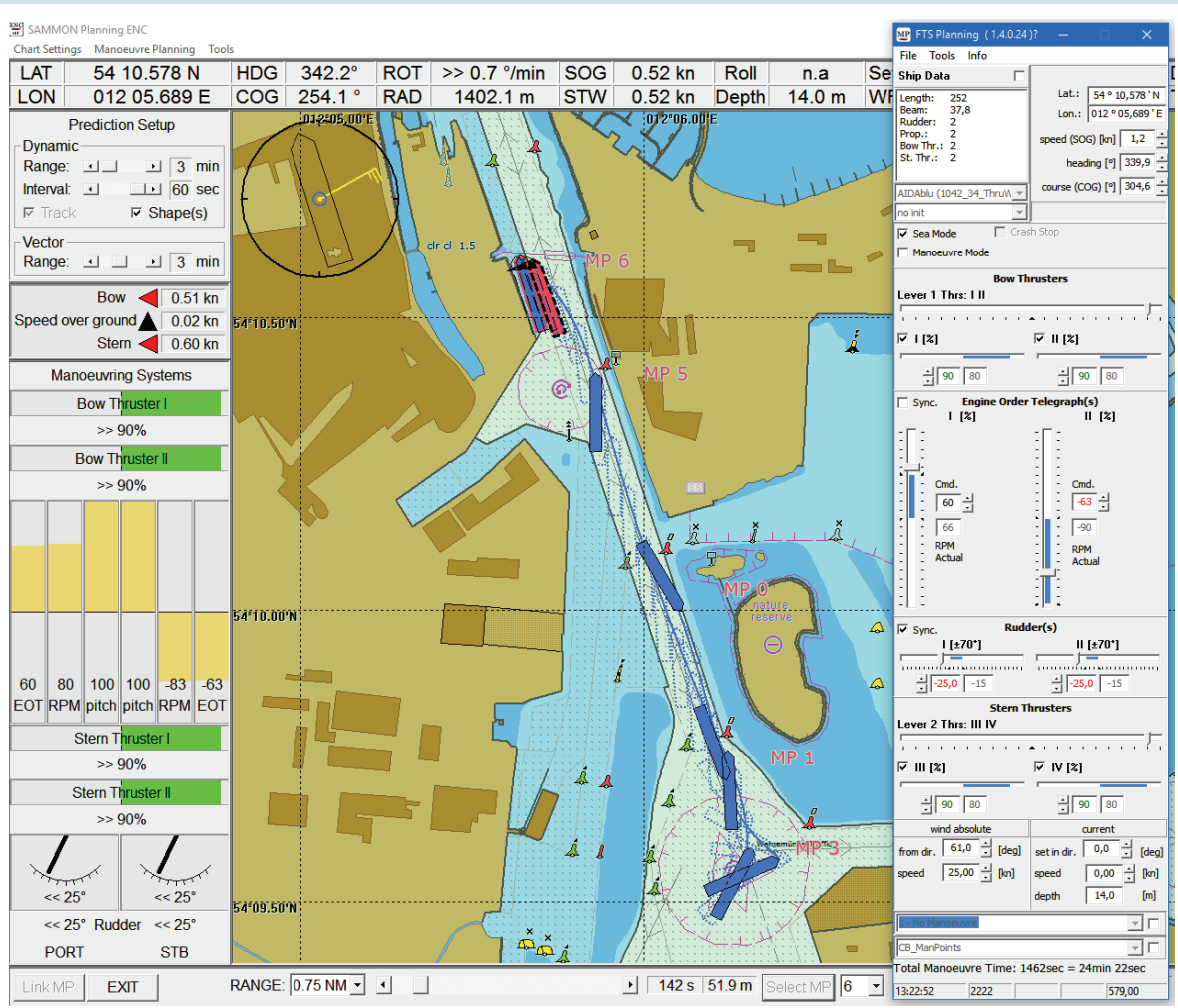

Figure 14.

Complete manoeuvring plan with the final berthing manoeuvre. 
stop since one engine is already going astern and there is no additional reversing time. On the right side of the figure, the stopping manoeuvre requires the trainee to bring the ship into a position parallel to the berth. In Figure 14 thrusters and rudders work at full power to counteract the wind for the final berthing, the approaching speed of the drift motion towards the pier is below $0.8 \mathrm{kn}$ (for $30 \mathrm{kn}$ it would be over $1.5 \mathrm{kn}$ ).

\subsubsection{Briefing by means of the "Manoeuvre Trial $\&$ Training module"}

The Trial \& Training Tool is a desktop simulation tool for real time manoeuvring simulation illustrated in Figure 13. It has the same handle panel on the right side as previously seen in the planning tool. It contains conning information, together with prediction and is capable of displaying the planned manoeuvring track. The central window shows the ENC with motion parameters for longitudinal and transverse speed. The ship's position is displayed in the centre of the ENC as the ship's contour. Track prediction can also be indicated here either as a curved track or a chain of contours for the selected prediction time. Prediction parameters, like presentation range or interval, can be set in the control window on the left side.
In Figure 13 the scenario of navigation under wind is shown, with the ship just having entered the turning area and beginning to turn. The table at the top of the ENC shows planned manoeuvre control settings, with the planned track designated by blue colour.

\section{EXECUTION OF EXERCISE AND DEBRIEFING WITH FAST TIME SIMULATION}

\subsection{Use of Simulation-Augmented Support with SAMMON Monitoring Tool in a Ship Handling Simulator}

There are several ways to support execution and debriefing with FTS.

Support during exercise execution depends on the extent to which the trainee is allowed to use the new manoeuvring prediction technology during the exercise.

- At the lower end, multiple dynamic prediction can be used to gradually introduce the student to potential control options at his disposal, as a means of good visualisation of manoeuvre quality - in this case, only the learning process is supported since the new technology is still unavailable on conventional ships.

- At the highest level, the trainees are allowed to make full

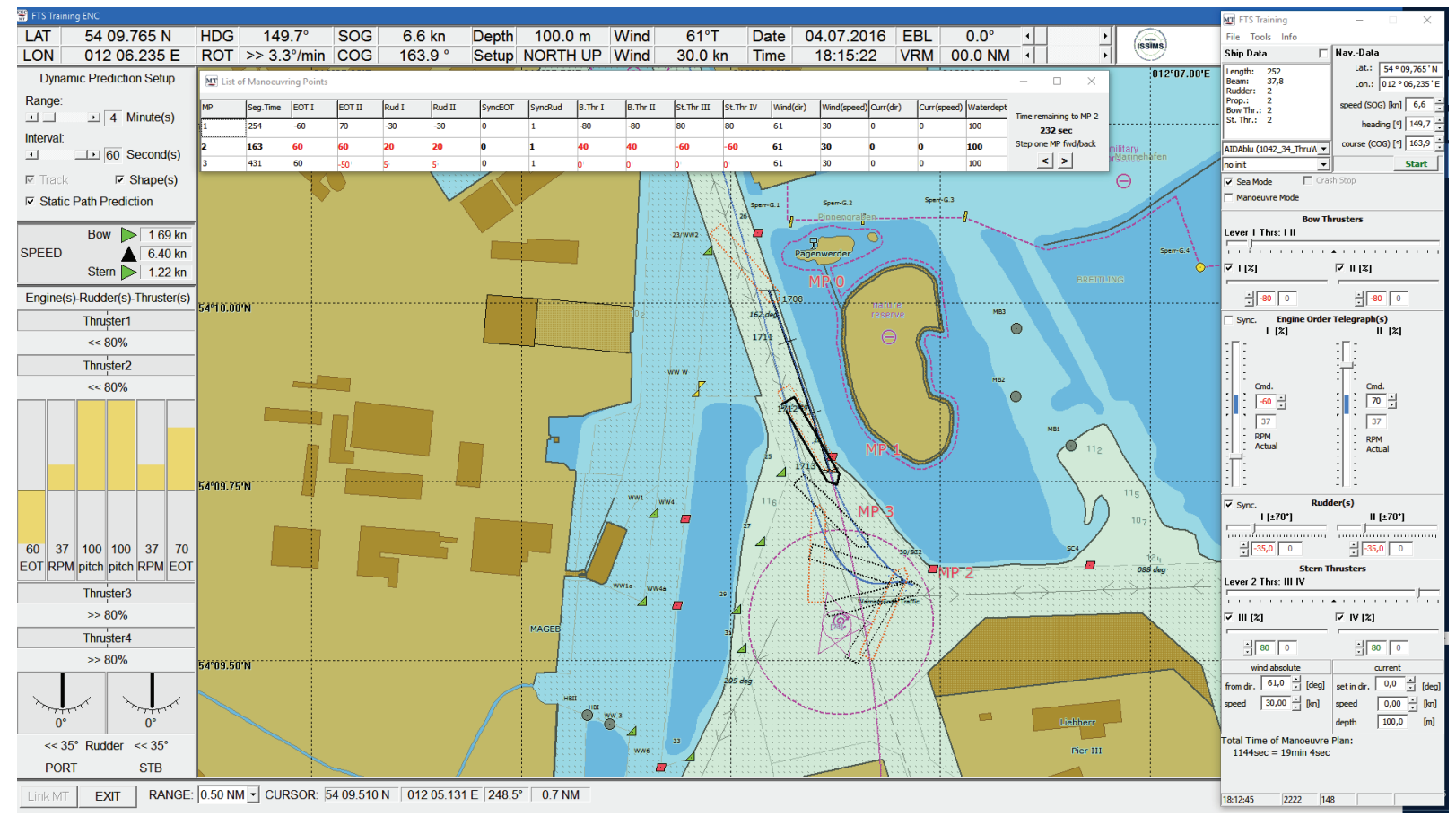

Figure 15.

SAMMON Trail \& Training Tool: real time simulation and manoeuvring prediction integrated into ECDIS, with the comparison of full dynamic prediction (dotted ship contours) and simple static prediction (magenta curve), together with planned manoeuvring track (blue line) (same in Monitoring Tool, with the exception of the handle panel). 
use of dynamic prediction and the prepared manoeuvring plan, they, as a rule, come closest to realizing the plan and get the best exercise results. The full use of prediction raises the safety and effectiveness even of advanced trainees

- $\quad$ Multiple dynamic predictions are always of great help to instructors (and peer students) because the chance for a trainee's action to be successful can immediately be seen and the exercise may be terminated earlier if it is obvious that the trainee will fail.

In the debriefing, fast time tools allow for an in-depth assessment of the quality of manoeuvring results:

- The assessment of results by comparison with the trainee's own concept or optimised plan can be shown in the replay function of the Monitoring tool, which can be used with the

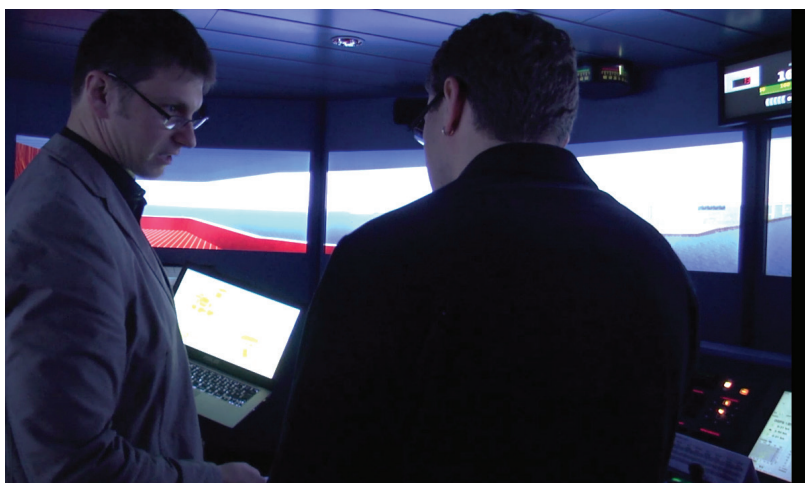

Multiple Prediction functionality; or in the SIMDAT tool for more detail, where the history of the trainee's actions can be presented graphically, e.g. for rudder, thruster and engine activities.

- Discussion of alternative manoeuvres at specific select situations can be supported by the Design \& Planning tool; a particular situation is loaded during the exercise run and the manoeuvring handles are operated in several different ways.

Multiple prediction can be useful for manoeuvres during the exercise. In Figure 16 the setup is either explained by the instructor or laptop is brought to the simulator bridge (where the manoeuvring plan might have been developed), the prediction is controlled by the bridge handles. The same laptop with the Monitoring tool can also be placed at the instructor's station.

Figure 16.

Using Multiple Prediction in simulator training at the AIDA Cruises MSTC in Rostock:

- Left: portable setup for prediction display in the Monitoring tool on a trainee's laptop on the bridge - the prediction is controlled by the bridge handle via WLAN

- Right: prediction display in a debriefing session (left screen): dynamic prediction can be used even during fast replay to complement the simulator instructor display (right screen).

The benefits of FTS use are:

- Multiple dynamic predictions shown on the instructor's screen are always of great help to instructors and maybe even peer students looking over their shoulders to learn from the actions of the other trainees in charge on the bridge. They have a better overview of the current situation and the chances for a trainee's action to succeed can be seen immediately; the exercise can be stopped earlier if it is obvious that the trainee will fail.

- Multiple dynamic prediction can be used to gradually introduce the student to potential control options at his disposal, as a means of good visualisation of manoeuvre quality - in this case, only the learning process is supported since the new technology is still unavailable on conventional ships.

- If the trainees are allowed to make full use of dynamic prediction and the prepared manoeuvring plan, they, as a rule, come closest to realizing the plan and get the best exercise results. The full use of prediction raises the safety and effectiveness even of advanced trainees and can support the identification of the best performance.

\subsection{Debriefing On the Exercise and Comparison of Results With the Manoeuvring Plan}

There are several debriefing methods available after the training, using the FTS software. Whilst the Ship Handling Simulator (SHS) allows the training session to be additionally recorded using the "Monitoring \& Manoeuvring Module", the training and planning procedure can also be saved in the "Trial \& Training", as well as in the "Manoeuvre Design \& Planning" modules. All files pertaining to planning and execution can be shown together, both in the form of the ship's track, and as diagrams for several parameters throughout the manoeuvring time in the SIMDAT program. The following figures illustrate some of the possible result display methods.

In Figure 17 two simulator results of trainees with a different level of preparation are compared mutually and with the manoeuvring plan of the second trainee. The achievements of the better prepared trainee are obvious - the actually executed track comes very close to the planned manoeuvre and the actions 

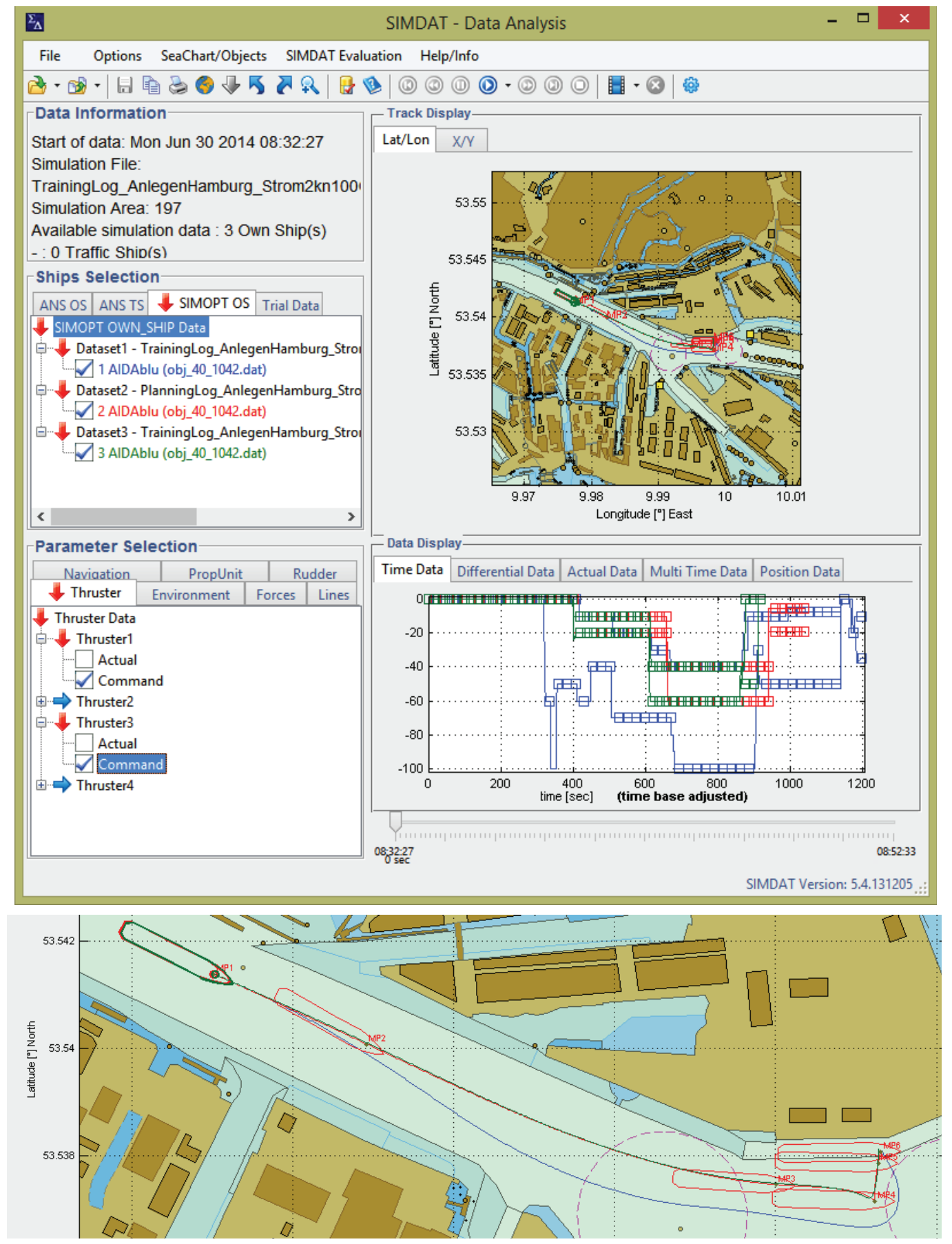

Figure 17.

Results from two manoeuvring exercises in SIMDAT interface (Top: "Track Display" with contours; Blow: "Data Display" of thruster activity history, Bottom: extract of sea chart from Track Display) and comparison with the prepared manoeuvring plan (below):

- Blue: run of the trainee without Fast Time Simulation support

- Green: run of the trainee with full support and pre-planning with the Design and Planning module

- Red: prepared manoeuvring plan with manoeuvring points MP. 
of the controls also closely mimic the planned procedures. The use of the Fast Time Simulation tool in briefing and training not only reduces manoeuvring time; the thruster diagrams also show that a well-prepared manoeuvre can minimize the use of propulsion units, which makes the manoeuvre more efficient. Another great benefit of Fast Time Simulation is the opportunity to discuss alternative manoeuvres, the effects of and strategies of coping with different environmental conditions which might affect the ship unexpectedly at critical positions.

\section{CONCLUSIONS / OUTLOOK}

Fast Time Manoeuvring simulation has proven to be beneficial both for lecturing and training intended to improve ship handling knowledge and skills. The huge potential of this technology will be explored further, until it is incorporated onboard real ships. The majority of participants of ship handling courses hold that the Design \& Planning module could be used for the compilation of a berthing plan onboard ships. There is high potential for optimisation, which would reduce manoeuvring time and fuel consumption /emissions. The FTS could also prove to be useful in various analyses (e.g. fairway layout, accidents) aiming to identify measures which would make shipping safer. Finally, the potential for real ship operation is obvious, e.g. for the information exchange between a pilot and the bridge team. The same tools may be applied to visualize intended plans of a pilot, monitor its conduction or discuss alternative maneuvering strategies and potentials threats respectively.

\section{ACKNOWLEDGEMENTS}

The research results presented in this paper were partly achieved in research projects "Multi Media for Improvement of MET" - MultiSimMan and the follow-up project MultiSimMan-GREEN, funded by the German Federal Ministry of Education and Research (BMBF), surveyed by Research
Centre of the German Space Agency DLR Bonn. Additionally it has to be mentioned that the professional version of the SAMMON software tools has been further developed by the startup company Innovative Ship Simulation and Maritime Systems GmbH (ISSIMS GmbH).

\section{REFERENCES}

Benedict, K., (2016), Control your pivot point position in Ship Handling - Multimedia approach by Fast Time Simulation, IMSF 2016, AGM Seminar, June $13^{\text {th }}-16^{\text {th }}$, Ship handling Research and Training Centre llawa / Poland.

Benedict, K., Baldauf, M., Felsenstein, C., Kirchhoff, M., (2003), Computer-based support for the evaluation of ship handling simulator exercise results, MARSIM - International Conference on Marine Simulation and Ship Manoeuvrability, Kanazawa, Japan, August $25^{\text {th }}-28^{\text {th }}$, pp. $70-79$.

Benedict, K., Baldauf, M., Fischer, S., Gluch, M., Kirchhoff, M., Schaub, M., Klaes, S., (2012), Fast Time Manoeuvring Simulation as Decision Support for Planning and Monitoring of Ship Handling Processes for Ship Operation Onboard and Training in Simulators, MARSIM - International Conference on Marine Simulation and Ship Manoeuvrability, Singapore, April $23^{\text {th }}-27^{\text {th }}$, pp. 803-819.

Benedict, K., Baldauf, M., Fischer, S., Gluch, M., Kirchhoff, M., Schaub, M., Krueger, C-P., Klaes, S., (2016), Simulation Technology brings new visualisation of the future ships path - and advanced use of the well-known Speed Vector, The 24th International Maritime Lecturers Association Conference, Quality Standards in Maritime Education, November $10^{\text {th }}-14^{\text {th }}$, Texas A \& M University at Galveston, TX /USA.

Benedict, K., Baldauf, M., Kirchhoff, M., Koepnick, W., Eyrich R., (2006), Combining Fast-Time Simulation and Automatic Assessment for Tuning of Simulator Ship Models, MARSIM - International Conference on Marine Simulation and Ship Manoeuvrability, Terschelling, Netherlands, June $25^{\text {th }}-30^{\text {th }}$, Proceedings, M-Paper 19 pp. 368-376.

ISSIMS GmbH Web page for SIMOPT \& SIMDAT, available at: https://www.issimsgmbh.com/yoomla/, [accessed at 25 February 2017].

Schaub, M., Benedict, K., Gluch, M., Milbradt, G., Tuschling, G., Kirchhoff, M., (2015), Modelling of Ships for Simulator-Training and simulation-augmented Manoeuvring Support on board and from the shore, MARSIM - International Conference on Marine Simulation and Ship Manoeuvrability, Newcastle, September $8^{\text {th }}-11^{\text {th }}$. 